\title{
Barriers and drivers of voluntary blood donation in northern
}

\section{and Western Tanzania [version 1; peer review: 1 not approved]}

\author{
Florian Finda ${ }^{1,2^{*}}$, Marceline Finda $3{ }^{3} 4^{*}$, Ally Olotu 5
}

\author{
${ }^{1}$ Life Science and Bioengineering, 1. Nelson Mandela African Institution of Science and Technology, Arusha, Tanzania, 0000 , \\ Tanzania \\ ${ }^{2}$ Research and Training, Ifakara Health Institute, Bagamoyo, Tanzania, 0000, Tanzania \\ 33. Environmental Health and Ecological Sciences Department, Ifakara Health Institute, Ifakara, Tanzania, 0000, Tanzania \\ 44. School of Public Health, Faculty of Health Sciences, University of the Witwatersrand, Johannesburg, South Africa, 0000, South \\ Africa \\ 5Intervention and Clinical Trial, 5. Ifakara Health Institute, Bagamoyo, Tanzania, 0000, Tanzania \\ * Equal contributors
}

V1 First published: 09 Feb 2022, 5:6

https://doi.org/10.12688/aasopenres.13313.1

Latest published: 09 Feb 2022, 5:6

https://doi.org/10.12688/aasopenres.13313.1

\section{Abstract}

Introduction: Every second, someone in the world needs blood due to surgery, trauma, severe anemia or pregnancy complications. There is a shortage of blood for transfusion worldwide, with the heaviest burden faced by sub-Saharan Africa. In countries like Tanzania, the major source of blood is voluntary blood donation, making its supply one of the most challenging in the health care system. This study assessed the magnitude of the deficit of blood in blood banks, and explored views of key stakeholders on the need, availability and opportunities for improving blood donations in northern and Western Tanzania.

Methods: This was an explanatory sequential mixed method study done in the Mpanda and Moshi districts in the Katavi and Kilimanjaro regions. A quantitative component involved a questionnaire survey with 253 community members from the two districts and 24 months blood bank records. The survey explored awareness and perceptions of voluntary blood donation. A qualitative component involved four focus group discussions with registered voluntary blood donors and health care providers from the National Blood Transfusion Service in the two districts.

Results: Blood bank records indicated that more blood was collected in Katavi compared to the Kilimanjaro region. Only $26 \%$ of the survey respondents had ever donated blood in their lifetime, three quarters of these were from Mpanda district. There was no significant association between socio-demographic factors and likelihood of blood donation. However, being male, older (51 years and above), having higher household income and secondary school education were significantly associated with higher awareness of voluntary blood donation. Community sensitization, education, incentives and

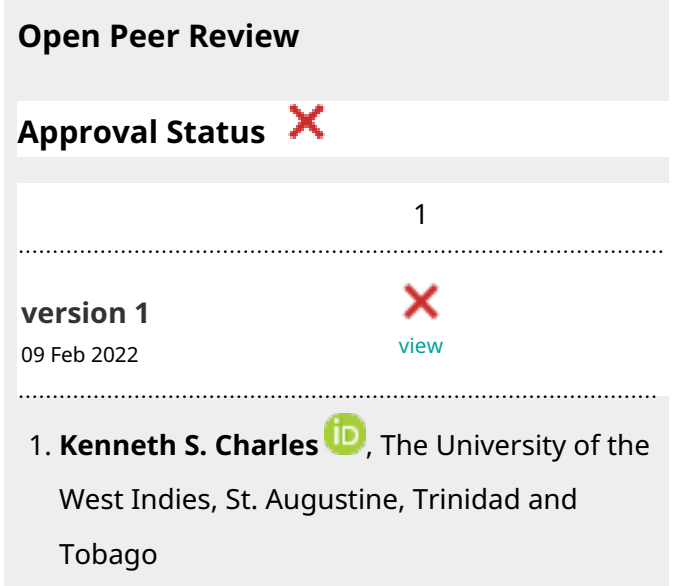

Any reports and responses or comments on the article can be found at the end of the article. 
availability of blood donation centers near communities were among the most important factors listed to improve blood donation.

Conclusions: Significant efforts need to be placed on sensitization and improving knowledge and awareness of voluntary blood donations in order to improve its uptake.

Keywords

Blood, donations, voluntary, Tanzania

Corresponding authors: Florian Finda (ffinda@ihi.or.tz), Marceline Finda (Ifinda@ihi.or.tz)

Author roles: Finda F: Conceptualization, Data Curation, Formal Analysis, Funding Acquisition, Investigation, Methodology, Project Administration, Resources, Software, Supervision, Validation, Visualization, Writing - Original Draft Preparation, Writing - Review \& Editing; Finda M: Conceptualization, Data Curation, Formal Analysis, Funding Acquisition, Investigation, Methodology, Software, Supervision, Validation, Visualization, Writing - Original Draft Preparation, Writing - Review \& Editing; Olotu A: Conceptualization, Supervision, Writing - Review \& Editing

Competing interests: No competing interests were disclosed.

Grant information: This research was supported by the African Academy of Sciences under a DELTAS Africa Initiative grant [107768] as part of the Consortium for Advanced Research Training in Africa (CARTA) awarded to MF. CARTA is jointly led by the African Population and Health Research Center and the University of the Witwatersrand and funded by the Carnegie Corporation of New York [G-19-57145], Sida [54100113], Uppsala Monitoring Centre and the DELTAS Africa Initiative [107768]. The DELTAS Africa Initiative is an independent funding scheme of the African Academy of Sciences (AAS)'s Alliance for Accelerating Excellence in Science in Africa (AESA) and supported by the New Partnership for Africa's Development Planning and Coordinating Agency (NEPAD Agency) with funding from the Wellcome Trust [107768] and the UK government. The views expressed in this publication are those of the authors and not necessarily those of AAS, NEPAD Agency, Wellcome Trust or the UK government. FF was also supported by Ifakara Health Institute's Training department. The funders had no role in study design, data collection and analysis, decision to publish, or preparation of the manuscript.

Copyright: $\odot 2022$ Finda F et al. This is an open access article distributed under the terms of the Creative Commons Attribution License, which permits unrestricted use, distribution, and reproduction in any medium, provided the original work is properly cited.

How to cite this article: Finda F, Finda $\mathrm{M}$ and Olotu A. Barriers and drivers of voluntary blood donation in northern and Western Tanzania [version 1; peer review: 1 not approved] AAS Open Research 2022, 5:6 https://doi.org/10.12688/aasopenres.13313.1

First published: 09 Feb 2022, 5:6 https://doi.org/10.12688/aasopenres.13313.1 


\section{Introduction}

Every second, someone in the world needs blood ${ }^{1}$. Surgery, trauma, severe anemia and complications of pregnancy are among the clinical conditions that demand blood transfusion. According to the World Health Organization (WHO), the world needs 305 million units annually. However, only about 272 million units were available in $2017^{1}$. The need for blood varies greatly from country to country ${ }^{2}$. Higher income countries require transfusions mostly for injuries or chronic conations such as anemia, sickle cell disease, a bleeding disorder such as hemophilia, or cancer compared to lower income countries where infectious diseases, respiratory illness, or nutritional deficiencies are more common reasons for transfusions ${ }^{2}$. In Tanzania for example, the most common reasons for blood transfusion include maternal hemorrhage, anemia as a result of various infectious and sickle-cell disease, malnutrition and road traffic accidents ${ }^{1,3-5}$.

In Tanzania with a population of 54 million people, 540,000 units of blood were needed in $2020^{1,6}$. However, in 2016 less than 200,000 blood units were collected, creating a shortage of more than 300,000 blood units. Moreover, $15 \%$ of the collected units were not approved due to the various reasons, further decreasing the amount of useful blood ${ }^{6,7}$. Health-related Millennium Development Goals to reduce child mortality improve maternal health and prevent human immunodeficiency virus (HIV) infection cannot be achieved without equitable and universal access to safe blood ${ }^{1,8}$.

Supply of blood is one of the most challenging issues in healthcare ${ }^{9}$. Since blood is a highly perishable product, transport between the donation point, processing unit (blood bank) and delivery to the end consumer should be fast and cost-effective ${ }^{10}$. The Tanzanian government has recently established a centrally organized blood transfusion system, the National Blood Transfusion Services in Tanzania (NBTS) ${ }^{6,11,12}$. NBTS operates a network of seven blood centers countrywide, namely; Lake Zone, Northern Zone, Southern, Eastern, Southern Zone and Tanzania People's Defense Forces ${ }^{10}$. However, NBTS faces several challenges including limited blood donors, inadequate human resource, infrastructure and funding to ensure safe and adequate blood supply ${ }^{10}$.

To shed light on current challenges and opportunities for improvement in access and utilization of blood in Tanzania, this study set to assess the magnitude of the deficit of blood in blood banks, explore views of health care workers regarding inadequacies in blood supply in health facilities, and explore and assess perceptions of community members regarding voluntary blood donations.

\section{Methods}

\section{Study site}

This study was conducted in the Kilimanjaro region in northern Tanzania and the Katavi region in western Tanzania between March and November 2020. In Kilimanjaro this study was done in the Longuo and Pasua wards in Moshi Municipal council. Moshi has a population of approximately 300,000 people who are mainly involved in trade and commerce, animal husbandry (zero grazing) and crop production. The council is a home to two referral hospitals; Kilimanjaro Christian Medical Center (KCMC) and Mawenzi regional hospital, and numerous smaller hospitals, dispensaries and health centers. Only four hospitals provide blood transfusion services in the council $^{13}$. In the western zone our study was done in the Mpanda district of the Katavi region, in the Ilembo and Ikola wards. Mpanda district has a population of approximately 500,000 people who are mainly farmers, pastoralists and fishermen. There is one referral hospital in the district, Mpanda regional referral hospital (MRH), and several smaller hospitals and health centers. MRH is the only hospital that provides blood donation services in the district ${ }^{13}$.

\section{Study design and data collection}

This was an explanatory sequential mixed methods study design $^{14}$. The quantitative component involved a questionnaire survey with residents of the two districts to explore their awareness and perceptions of voluntary blood donation. Data on amount of blood donated and usage at the blood banks was also collected from blood banks in the two districts. The qualitative component of the study involved focus group discussions (FGDs) with staff of blood banks as well as voluntary blood donors to explore challenges that the blood banks face in getting blood donations and more insights into perceptions of resident regarding voluntary blood donations. The voluntary donors were identified from the registries of voluntary blood donors at the donation centers during donation procedures.

\section{Survey questionnaire: \\ Sample}

Sample size was calculated by using likelihood ratio test for comparison of two independent proportions for cross-sectional studies. 30\% proportion of blood donation was used (Elias et al., 2016) to calculate the required sample size for testing community members knowledge, attitude and practice in voluntary blood donation (survey questionnaires).

After constructing the questionnaires, the scientists from Ifakara Health Institute experienced with qualitative research were widely consulted to check on appropriateness and on ease of use of the questionnaires before finalizing them and deploy them in the field.

Likewise, information about drivers and barriers to voluntary blood donation was collected though four focused group discussion (two from each region) with 24 participants (12 from each region). Assuming a significance level of $5 \%$, power of $90 \%$, ability to detect a $20 \%$ difference in proportion between the two populations, and consent refusal rate of $10 \% 278$ participants were required, 139 from each region. An equal number of voluntary blood donors and employees of NBTS were collected in the two regions for a total sample size of 278 participants.

In the first stage of the sampling, Mpanda and Moshi urban districts were selected using purposive sampling from 
Katavi and Kilimanjaro regions, respectively. In the second stage of sampling, two wards were randomly selected from each of the two districts from the list of available wards in each district. Then, systematic sampling technique was employed to select households randomly from each of the ward. The numbers of households sampled from the selected wards were determined using proportionate-to-population size.

Eligibility for focus group discussions was determined based on involvement of participants in the process of strategy development and/or recruitment of donors to promote voluntary blood donation. The voluntary blood donors were selected randomly from the pool of registered donors who have recently (within the last 12 months). Employees of NBTS were selected depending on their willingness to participate and time favorable to them.

To minimize selection bias, households were randomly selected using excel RAND function from a list of households obtained from each ward office. The households were then visited by the study team with help from ward leaders. From each household only two participants were recruited. They had to be 18 years or older and mentally fit. They had to either be a head of the household, elder sons or daughters. In the case of failure to find an eligible participant in a selected household, the selected household was closed, or if a participant refused to consent, next household in the clockwise direction was visited and recruited. The aim of the survey was to assess a) awareness of voluntary blood donation services, b) whether the respondents have ever donated blood and reasons associated, c) perceptions associated with voluntary blood donation and d) opinions of the survey respondents on how voluntary blood donation can be improved. The survey was administered in Swahili, the Tanzanian national language via electronic tablets. Kobo toolbox, a free-access software program was used by the investigators to generate electronic forms, and administer the survey by filling the respondents' responses in the forms ${ }^{15}$. To minimize non-response bias, adults $>18$ years and who were likely to be the heads of the households were recruited and questionnaires were administered by the investigators to individual participants when not in the presence of other household members to ensure they freely gave their responses. To minimize gender biasness, both men and women were recruited in both survey and FGDs in both regions. To minimize authors' biasness the study was reviewed by all three authors.

Focus group discussions: A total of four FGD sessions were conducted, two from each district. All the FGDs took place in the quiet environment and took place in 20 to 30 minutes. Employees of NBTS selected the convenient time for them and the FGDs took place in one of the rooms in NBTS in both centers. All the team members have good knowledge and experience in qualitative data collection. Of the four FGD sessions, two were with registered voluntary blood donors selected randomly from the blood bank registry where their mobile phone numbers were found, and two sessions were conducted with representatives of Tanzania's National Blood Transfusion Service (NBTS) staff. These participants were selected and recruited via direct voice phone calls upon their availability and willingness to participate. Each FGD session was comprised of 6 participants, and the discussions lasted between 50 and 90 minutes. The discussions were audio-recorded upon consent from the participants. A semi-structured discussion guide was used, with open-ended questions guiding the discussions. To minimize selection bias; both blood donors and NBTS staff were randomly selected using excel RAND function from registries of their names while non-response bias was minimized by having separate FGD sessions for male and female participants as well as probing participants for additional views or differences in perspectives for each question.

Blood donation and usage records: Blood bank records for 2019 and 2020 were reviewed from the Kilimanjaro and Katavi regions. The records were obtained from the regional medical officer's office and included information on the amount of blood collected, distributed and discarded as well as the reason for discarding it. Demographic information of blood donors was also collected.

\section{Data processing and analysis}

Quantitative data analysis: Survey data were organized and checked every day at the field for errors. Upon completion of data collection, the data was transferred to excel for further cleaning, and analysis was done using $\mathrm{R}$ statistical software version 4.0.0. For continuous variables, means with their respective measures of dispersion were used while proportions were used for categorical data. Univariate and multivariate analyses were used to assess association between independent (sociodemographic characteristics) and outcome variables (perceptions towards voluntary blood donation and having donated blood); odds ratio (OR) was calculated at $95 \%$ confidence intervals (CIs).

Qualitative data analysis: The recorded transcripts were transcribed verbatim, translated into English by Florian Finda and incoperated into qualitative analysis software (Nvivo version 10) by Marceline Finda for analysis. The objective of the study and FGD guide, were used to develop deductive or topic codes. A coding framework with definitions was applied to all the transcripts and field notes. The codes were further grouped, and emerging patterns were used to identify themes.

\section{Ethical considerations}

Ethical approval for this project was obtained from Ifakara Health Institute's Institutional Review Board (Protocol ID: IHI/IRB /No: 36 - 2020). Meetings with heads of the units and communities were conducted to provide information on the study and ask for permission to conduct the study. Written informed consent was obtained from all study participants. Both Northern zone and Western Blood banks provided the blood donation records and gave permission to use them in this study. All blood bank data are anonymous.

\section{Results}

Characteristics of the study participants

A total of 277 people participated in this study; 253 community members participated in the survey and 24 who participated in the FGDs ${ }^{16}$. Of the 253 community members who responded 
to the survey, approximately half $(53 \%, n=134)$ were males and $47 \% \quad(n=119)$ were females (Table 1). In terms of representation, $45 \% \quad(n=114)$ of the respondents were from the Mpanda district and 55\% ( $n=139)$ were from the Moshi district. The overall average age was 42 years, ranging from 18 to 75 years. About a third of the respondents $(31.2 \%, \mathrm{n}=79)$ had primary education, another one third $(31.2 \%, \mathrm{n}=79)$ had college education and about one fifth $(22.1 \%, \mathrm{n}=56)$ had secondary school education. Only a few participants had no formal education, and a few had university education (Table 1). Average monthly household income was 387,181 Tanzanian shillings (TZS), equivalent of about 176 USD (1USD was equivalent to 2,200 TZS in November 2020, at the time this manuscript was being written). Farming and entrepreneurship were the major income generating activities (Table 1).

The 24 participants of the FGDs equally represented the two districts, and were equally divided between blood bank staff and blood donors. Fourteen of the participants were males and ten were females. The average age of the FGD participants was 35 years, ranging from 23 to 44 years.

Factors associated with voluntary blood donations

Approximately a quarter $(26 \%, n=66)$ of the survey respondents had ever donated blood in their lifetime. A majority
( $76 \%, \mathrm{n}=50$ ) of those that had ever donated blood were from the Katavi region and 24\% $(n=16)$ were from the Kilimanjaro region. Nearly all had donated between 1 to 5 times over the past 12 months; only one respondent had donated more than 5 times over the past 12 months. The major reasons for donating blood were to help family members $(30 \%, \mathrm{n}=40)$, help friends $(25 \%, \mathrm{n}=33)$, after receiving education on voluntary blood donations $(23 \%, \mathrm{n}=31)$ and just for the sake of volunteering $(21 \%, n=29)$. Due to the significantly low numbers of respondents that had ever donated blood, no significant associations were observed

With regards to awareness of voluntary blood donation services, approximately a half $(47.0 \%, \mathrm{n}=118)$ of all respondents were aware of voluntary blood donation. Some of the most popular sources of information included outreach visits by the health care providers, radio programs, internet as well as posters and billboards. Factors associated with awareness for voluntary blood donations included location, age, educational level, income level and knowledge of blood group (Table 2). Respondents from Mpanda were more than five times as likely to be aware of voluntary blood donation blood compared to respondents from Moshi (Table 2). Respondents with college education and above were more than 34 times as likely to be aware of voluntary blood donations compared to respondents

\begin{tabular}{|c|c|c|c|}
\hline & Mpanda & Moshi & Total \\
\hline \multicolumn{4}{|l|}{$\operatorname{sex}$} \\
\hline Male & $52 \%(n=59)$ & $54 \%(n=75)$ & $134(53 \%)$ \\
\hline Female & $48 \%(n=55)$ & $46 \%(n=64)$ & $119(47 \%)$ \\
\hline Average age in years & 40.9 & 43.4 & 42.2 \\
\hline Average income in TZS & $485,701.8$ & $397,388.5$ & 387,181 \\
\hline \multicolumn{4}{|l|}{ Educational level } \\
\hline Uneducated & $4 \%(n=10)$ & $2 \%(n=5)$ & 15 \\
\hline Primary & $21 \%(n=53)$ & $10 \%(n=26)$ & 79 \\
\hline Secondary & $10 \%(n=26)$ & $12 \%(n=30)$ & 56 \\
\hline College & $14 \%(n=35)$ & $17 \%(n=44)$ & 79 \\
\hline University & $6 \%(n=15)$ & $4 \%(n=9)$ & 24 \\
\hline \multicolumn{4}{|l|}{ Economic activities } \\
\hline Entrepreneurship & $30(20 \%)$ & $51(29 \%)$ & 81 \\
\hline Farming & $51(37 \%)$ & $64(37 \%)$ & 115 \\
\hline Formal employment & $8(5 \%)$ & $2(1 \%)$ & 10 \\
\hline Animal husbandry & $14(9 \%)$ & $15(9 \%)$ & 29 \\
\hline Fishing & $47(31 \%)$ & $32(18 \%)$ & 79 \\
\hline Unemployed & $3(2 \%)$ & $11(6 \%)$ & 14 \\
\hline
\end{tabular}


Table 2. Multivariate analysis of factors associated with awareness of voluntary blood donation. TZS=Tanzanian shillings.

\begin{tabular}{|c|c|c|}
\hline Variable & Odds ratio $(95 \% \mathrm{CI})$ & p-value \\
\hline \multicolumn{3}{|l|}{ Location } \\
\hline Moshi & Ref & - \\
\hline Mpanda & $5.36(3.12,9.20)$ & $<0.005^{* *}$ \\
\hline \multicolumn{3}{|l|}{ Sex } \\
\hline Male & Ref & - \\
\hline Female & $1.42(0.86,2.33)$ & 0.17 \\
\hline \multicolumn{3}{|l|}{ Age category (in years) } \\
\hline $18-30$ & Ref & - \\
\hline $31-40$ & $1.13(0.54,2.33)$ & 0.75 \\
\hline $41-50$ & $0.76(0.36,1.64)$ & 0.49 \\
\hline $51-60$ & $0.24(0.09,0.66)$ & $0.005^{\star \star}$ \\
\hline Above 60 & $0.35(0.12,0.97)$ & $0.04^{*}$ \\
\hline \multicolumn{3}{|l|}{ Educational level } \\
\hline No formal education & Ref & - \\
\hline Primary & $3.28(0.40,26.94)$ & 0.27 \\
\hline Secondary & $15.04(1.84,122.23)$ & $0.01 *$ \\
\hline College and above & $34.07(4.29,270.73)$ & $<0.005^{* *}$ \\
\hline \multicolumn{3}{|c|}{ Average monthly income (In TZS) } \\
\hline$<100,000$ & Ref & - \\
\hline $101,000-250,000$ & $2.47(0.80,7.60)$ & 0.11 \\
\hline $251,000-500,000$ & $3.23(1.13,9.19)$ & $0.028 *$ \\
\hline$>500,000$ & $11.62(6.30,41.62)$ & $<0.005^{* *}$ \\
\hline \multicolumn{3}{|l|}{ Knowledge of blood group } \\
\hline Know & Ref & \\
\hline Do not know & $0.05(0.026,0.094)$ & $<0.005^{\star *}$ \\
\hline
\end{tabular}

with no formal education, and respondents with income levels higher than 500,000 TZS were more than 11 times as likely to be aware compared to those with household income of less than 100,000 TZS. Last but not least, respondents who knew their blood group were 20 times as likely to be aware of voluntary blood donation compared to those who did not know their blood group (Table 2).

This difference between the two regions also came up during the FGD sessions with the NBTS staff from Mpanda, who stated that they raise community awareness regarding voluntary blood donations through several programs including through radio stations, community and conducting regular visits to the communities as these participants said:

"Yes we have different programs. These programs include radio program (Mpanda FM radio) which cover the whole Katavi region and some parts of Rukwa region, through this radio program we are able to reach allot of the people within a very short period of time and make them understand the importance of voluntary blood donation as well as clearing the wrong beliefs about the blood donation." (Female NBTS staff member from Katavi).

"Another program we use is ensuring that all the donors get their results on time. We visit one site after three months so when we go for the next visit we make sure that we have the results with us. This motivates the donors and makes them keep on donating blood as well as getting the new recruits." (Female NBTS staff member from Katavi).

As for the majority $(74 \%, n=192)$ of respondents that had never donated blood in their life, major reasons provided included fear of exposure to diseases, fear of losing too much blood, fear of being anemic, fear of losing sex libido and fear of knowing the health status. Other reasons given were lack of knowledge of donation centers, large distances between their homes and donations centers and cultural and religious reasons. These reasons were further elaborated during FGDs with voluntary blood donors who said:

"The main reason is the interest and poor education about the voluntary blood donation. Most of the people think that the blood is for sale so they don't donate for free." (Female blood donor).

"I once had unprotected sex so I thought that I had gotten infected with HIV/AIDS. From that day I never had peace of mind so I stopped donating for a long time because I am afraid that people might stigmatize me once they know my health issue. But one day I decided to take courage and went to the hospital and took HIV test, and I was clean, since then I have been donating regularly." (Male blood donor).

\section{Perceptions regarding voluntary blood donation}

Community members' perceptions towards blood donation are summarized in Table 3. The majority of survey respondents in both regions indicated that whether or not someone donates blood is dependent on several factors including health status (75\%), age (22\%) and religion or culture (2\%). Nearly a half $(48 \%, n=122)$ of all respondents believed that there were no health risks associated with blood donation. Of the $18 \%(n=45)$ that believed there are health risks associated with blood donation, the most feared risks included becoming anemic and exposure to diseases (Table 3). The majority $(76 \%, n=193)$ of respondents recommended that the most important way to improve voluntary blood donation would 
Table 3. Community member's perception on voluntary blood donation.

\begin{tabular}{|c|c|c|c|}
\hline Variables assessed & $\begin{array}{c}\text { Kilimanjaro } \\
(n=134)\end{array}$ & $\begin{array}{l}\text { Katavi } \\
(n=119)\end{array}$ & Total $(n=253)$ \\
\hline \multicolumn{4}{|l|}{ Can anyone donate blood? } \\
\hline Yes & $5 \%(n=13)$ & $6 \%(n=16)$ & $11 \%(n=29)$ \\
\hline No & $23 \%(n=55)$ & $12 \%(n=30)$ & $35 \%(n=85)$ \\
\hline It depends & $28 \%(n=71)$ & $26 \%(n=68)$ & $54 \%(n=139)$ \\
\hline \multicolumn{4}{|l|}{ Why can't everyone donate blood? } \\
\hline Health reasons & $42 \%(n=95)$ & $33 \%(n=73)$ & $75 \%(n=168))$ \\
\hline Age & $12 \%(n=26)$ & $11 \%(n=24)$ & $23 \%(n=50)$ \\
\hline Religion/cultural reasons & $2 \%(n=4)$ & $0.4 \%(n=1)$ & $2 \%(n=5)$ \\
\hline \multicolumn{4}{|l|}{ Are there health risks in donating blood? } \\
\hline Yes & $12 \%(n=31)$ & $6 \%(n=14)$ & $18 \%(n=45)$ \\
\hline No & $19 \%(n=47)$ & $29 \%(n=75)$ & $48 \%(n=122)$ \\
\hline I don't know & $24 \%(n=61)$ & $10 \%(n=25)$ & $34 \%(n=86)$ \\
\hline \multicolumn{4}{|l|}{ Health risks associated with blood donation } \\
\hline Losing blood and becoming anemic & $10 \%(n=27)$ & $5 \%(n=13)$ & $15 \%(n=40)$ \\
\hline Being exposed to the diseases & $6 \%(n=16)$ & $0 \%(n=0)$ & $6 \%(n=16)$ \\
\hline Against our culture & $2 \%(n=4)$ & $0 \%(n=0)$ & $2 \%(n=4)$ \\
\hline Becoming impotent & $0 \%(n=0)$ & $0.4 \%(n=1)$ & $0.4 \%(n=1)$ \\
\hline Fear of losing sex libido & $0 \%(n=0)$ & $0.4 \%(n=1)$ & $0.4 \%(n=1)$ \\
\hline \multicolumn{4}{|l|}{ How to improve voluntary blood donation } \\
\hline Educate and sensitize & $35 \%(n=88)$ & $41 \%(n=105)$ & $76 \%(n=193)$ \\
\hline Bring donation centers closer to people & $4 \%(n=9)$ & $5 \%(n=12)$ & $8 \%(n=21)$ \\
\hline Increase health care providers & $2 \%(n=5)$ & $3 \%(n=7)$ & $5 \%(n=12)$ \\
\hline Provide incentives & $2 \%(n=4)$ & $2 \%(n=4)$ & $3 \%(n=8)$ \\
\hline Increase donation centers & $3 \%(n=8)$ & $4 \%(n=9)$ & $7 \%(n=17)$ \\
\hline Not important to me & $1 \%(n=2)$ & $(n=0)$ & $1 \%(n=2)$ \\
\hline
\end{tabular}

be to educate and sensitize the community about this issue (Table 3). Other opportunities expressed were to bring donation centers closer to people, increase number of health providers at the donation centers to avoid long lines, to provide incentives for voluntary blood donors and to increase donation centers.

Levels of importance of the improvements in voluntary blood donation services were assessed using a 5-point Likert scale. The strategies assessed included 1) community sensitization, 2) community education and 3) bringing blood donation stations near people. More than $90 \%$ of all respondents deemed all these strategies to be very important in improving voluntary blood donation services (Table 4). Participants of the
FGDs also discussed other means that could be implemented to improve blood donation. These included improvement in the natational blood donation campaigns, recognition and appreciation of blood donors, and collaboration between different institutions in encouraging and facilitating blood donation services. The participants also advised that similar campaign approaches as those used on cervical and breast cancer should be used in improving voluntary blood donation. Here is a comment from one of the participants:

"Voluntary blood donation campaigns should be taken more seriously. They can be led by senior government officials like a president or prime minister. They should not be done on just a single day of the year, but throughout the year, the way campaigns 
Table 4. Community member's attitude on voluntary blood donation.

\begin{tabular}{|l|c|c|c|c|}
\hline Statement & $\begin{array}{c}\text { Very } \\
\text { important }\end{array}$ & $\begin{array}{c}\text { Slightly } \\
\text { important }\end{array}$ & $\begin{array}{c}\text { Not } \\
\text { important }\end{array}$ & $\begin{array}{c}\text { Don't } \\
\text { know }\end{array}$ \\
\hline How important is voluntary blood donation? & $90.5 \%(n=229)$ & $1.9 \%(n=5)$ & $2.8 \%(n=7)$ & $4.8 \%(n=12)$ \\
\hline How important is community sensitization? & $94.5 \%(n=239)$ & $1.6 \%(n=4)$ & $1.9 \%(n=5)$ & $1.9 \%(n=5)$ \\
\hline $\begin{array}{l}\text { How important is providing community with } \\
\text { education on voluntary blood donation? }\end{array}$ & $94.5 \%(n=239)$ & $1.6 \%(n=4)$ & $1.9 \%(n=5)$ & $1.9 \%(n=5)$ \\
\hline $\begin{array}{l}\text { How important is it to move blood donation } \\
\text { points near people? }\end{array}$ & $93.3 \%(n=236)$ & $2.4 \%(n=6)$ & $2 \%(n=5)$ & $3.4 \%(n=6)$ \\
\hline
\end{tabular}

against cervical cancer and breast cancer are done. In so doing there will be no blood shortage in the health centers." (Male blood bank staff).

\section{Amount of blood collected between April 2019 and November 2020}

The records of the amount of blood units donated between April 2019 and November 2020 in Kilimanjaro, and between January 2019 and November 2020 in the Katavi region were retrieved and assessed. The comparison was done for the period of April 2019 to November 2020 due to existence of records for both regions. A summary of the amount of blood collected in units is presented in Table 5. On average, more blood was collected in the Katavi region compared to that collected in the Kilimanjaro region. In both regions, males donated most of the blood, and more specifically, males who were voluntary blood donors (VBDs) donated about two thirds of all the blood donated (Table 5). In both regions more blood was collected from voluntary blood donors compared to family members, and more blood was collected from male compared to female donors (Table 5).

The difference in amount of blood donated between the two regions also came up during the FGDs with blood bank staff from Katavi who reported that the Katavi region was contributing most to the national blood bank compared to all other regions in the country. The staff reported some of the reasons for their success to be providing blood donors with cards that allow them preferential treatment at the hospital, and efficiency in providing blood test results as this participant said:

"We give priority to our voluntary blood donors when they come to the hospital to seek medical services as well as health care services. This helps them to get health care services earlier and go back to their businesses. This strategy motivates more people to come and donate blood as frequently as possible and this leads to enough blood supply to our blood bank. When we go to schools, we just tell the head of the school to give us time and date to talk to the students about the importance of voluntary blood donation, we sensitize them and when they are sensitized, they donate blood on the sport and get the blood donation card as well as the badge." (Female blood bank staff member from the Katavi region).

On the contrary, blood bank staff in Kilimanjaro reported several challenges that contributed to fewer collections including a lack of resources for conducting efficient blood testing and collections as this participant said:

"As a center we lack resources. We tell the donors that when we come back to the next visit, we will be having their results as all the tests take about two weeks to one month but due to the lack of resources we could not be able to give their results on time when we pay the next visit, so donors get demoralized and less motivated and this leads them to decide not to donate blood. As people need to know their status so they don't feel comfortable" (Male blood bank staff member from Kilimanjaro)

\section{Discussion}

Studies that assess challenges and opportunities for improving voluntary blood donations are essential in providing insights for successful implementation of voluntary blood donation programs and strategies to help maintain adequate and safe blood supply ${ }^{4,17,18}$. This study aimed to assess such factors from three different perspectives: community members, blood bank staff and voluntary blood donors in order to identify opportunities for improvement in voluntary blood donations in Tanzania.

Nearly half of the respondents in the two districts were aware of voluntary blood donation services, but only about a quarter reported having ever donated blood, which indicates that raising awareness does not necessarily increase blood donations. Similar findings have been observed in a study conducted in India where $87.3 \%$ of community members surveyed had never donated blood despite having adequate knowledge of the services ${ }^{19}$. The reasons listed for not donating blood, such as fears of being exposed to diseases, losing too much blood or revealing health status are also not unique to Tanzania. Similar studies by Matthew et al (2007) and Shidam in 2015 in India have also reported similar fears from potential donors ${ }^{19,20}$. 
Table 5. Amount of blood collected in Kilimanjaro and Katavi regions between April 2019 and November 2020. $\mathrm{VBD}=$ voluntary blood donor, 1 Unit of blood $=500 \mathrm{ML}$.

\begin{tabular}{|l|c|c|c|c|c|}
\hline & $\begin{array}{c}\text { All blood } \\
\text { collected (units) }\end{array}$ & Male VBD & Female VBD & Male family & Female family \\
\hline Kilimanjaro 2019 & 2,923 & $1,826(62.5 \%)$ & $787(26.9 \%)$ & $232(7.9 \%)$ & $78(2.7 \%)$ \\
\hline Katavi 2019 & 4,010 & $2,726(68.0 \%)$ & $614(15.3 \%)$ & $626(15.6 \%)$ & $44(1.1 \%)$ \\
\hline Kilimanjaro 2020 & 2,811 & $1,633(58.1 \%)$ & $730(26.0 \%)$ & $325(11.6 \%)$ & $123(4.4 \%)$ \\
\hline Katavi 2020 & 4,072 & $2,798(68.7 \%)$ & $796(19.5 \%)$ & $446(11.0 \%)$ & $32(0.8 \%)$ \\
\hline
\end{tabular}

Similar challenges have also been expressed across different settings in Africa and the Middle East, indicating a need to thouroughly sensitize communities about facts and fictions associated with blood transfusion ${ }^{4,5,17,21}$. These studies recommend that, in addition to raising awareness, providing adequate education that responds to peoples' fears will vastly improve blood donation ${ }^{20}$

A majority of the survey respondents had a positive attitude regarding donating blood in the future, but they needed to be educated and have their questions and concerns responded to. The impact of raising awareness was apparent in the gap in amount of blood collected between the two regions. Katavi had collected nearly twice the amount of blood that had been collected in Kilimanjaro region. Interestingly, blood bank staff from Katavi had reporting investing adequate resources in community sensitization efforts, and as expected, a majority of the survey participants that had reported donating blood were from the Katavi region. Some of the reasons given by those that had reported donating blood included the need by family, relatives or friends as well as advocacy and sensitization by health care providers. These findings are similar to those in a study by Smith et al (2016) who reported reasons such as the desire to save lives, and the need of blood in emergency situations ${ }^{22}$. It is crucial to raise awareness of community members on the need for blood, and their potential in saving lives.

Other recommendations to improve voluntary blood donations included bringing donation centers near the people, and providing incentives for people to donate blood. Incentives proposed included public recognition for the blood donors and preferential treatment at health care facilities. These recommendations are valid, and it was indicated that they were already being practiced to some extent in the Mpanda district which evidently had a majority of the blood donors as compared to Moshi and their blood bank had more blood compared to Moshi district. In this case the Moshi district has an opportunity to learn from Mpanda and adapt the techniques used in Mpanda to improve blood donations.

The strength of the study lay of the fact that it gathered information from various stakeholders of blood donation ecosystem. The information was collected from voluntary blood donors, employees of National Blood Transfusion Service (NBTS) and registered voluntary blood donors. Triangulation of this information provides a comprehensive picture of the important factors that influence blood donation in the country.

The main weakness of this study is that the study focused on two regions only and may not be generalized to the entire country. Because factors affecting donation could be influenced by cultural norms, we could not have exhausted all potential factors that played a role in determining blood donation. It is possible that the responses from respondents were biased. To avoid this bias the information was collected from different groups. These groups are community members of different age groups who are potential voluntary blood donors or have donated blood more than ones, registered voluntary blood donors and the employees of NBTS from both centers. Their views were triangulated with the records from the blood bank records from both centers.

\section{Conclusion}

This study recommends that more efforts need to be placed on sensitization and improving knowledge on perks of voluntary blood donations in order to clear misunderstandings and misconceptions, and hence improve the practice of voluntary blood donations. This study can be used to draw lessons of strategies that are employed by regions with higher voluntary blood donation rates so that the regions with moderate and lower voluntary donation rates can use to improve and reach their blood demand collection targets. Mass media and social media platforms can be used to provide such educational and motivational messages. Additionally, periodic awareness programs in voluntary blood donation are also needed even among the health workers to motivate people so that they can donate blood.

\section{Data availability}

\section{Underlying data}

Mendeley Data: Awareness, perceptions and practices of voluntary blood donations in western and northern Tanzania. https://data. mendeley.com/datasets/c6dkrj2bdd/ $3^{16}$.

This project contains the following underlying data:

KATAVI BLOOD DONATION REPORT (voluntary blood donation records from blood banks in Katavi region) 
- KILIMANJARO BLOOD DONATION REPORT (voluntary blood donation records from blood banks in Kilimanjaro region)

- FGD QUESTIONS WITH VOLUNTARY BLOOD DONORS.docx

- FGDs TRANSCRIPTS WITH SIX VOLUNTARY BLOOD DONORS IN MOSHI MUNICIPAL.docx

- FGDS TRANSCRIPTS WITH SIX VOLUNTARY BLOOD DONORS IN MPANDA DISTRICT.docx

- $\quad$ FGDs WITH QUESTIONS WITH BLOOD DONATION PERSONELS.docx

- $\quad$ FGD TRANSCRIPTS WITH EMPLOYEES OF BLOOD BANK FROM KATAVI.docx

- FGD TRNSCRIPTS KILIMANJARO WITH BLOOD BANK EMPLOYEES-KILIMANJARO.docx

- $\quad$ SURVEY QUESTIONNAIRES.docx
- $\quad$ Florian Finda blood survey 1_Clean_231120.xlsx

Data are available under the terms of the Creative Commons Attribution 4.0 International license (CC-BY 4.0).

\section{Acknowledgements}

The study team expresses their heartfelt thanks to the Ifakara Health Institute for sponsoring this study, all research scientists from Ifakara Health Institute. The team also extend thanks to President's Office - Regional Administrative and Local Governance (Katavi and Kilimanjaro regional offices) and Ministry of Health, Community Development, Gender, Elderly and Children - MoHCDGEC (National Blood Transfusion Service Northern and Western zone blood banks). Together they helped to make sure that we have everything we need to accomplish this study. We extend our special thanks to Regional Nursing officer and research coordinator from Kilimanjaro region Regional blood supply coordinator from Kilimanjaro region. Their tireless efforts in order to make sure that we have everything that we need, and made the team succeed in this work.
1. WHO: Global Status Report on Blood Safety and Availability. World Heal. Geneva; 2017.

Reference Source

2. Kuehn B: Widespread Blood Shortages Threaten Global Public Health. JAMA. 2019; 322(23): 2276

PubMed Abstract | Publisher Full Text

3. Hamilton AK, Hayton JC: Maternal mortality in sub-Saharan Africa: The contribution of ineffective blood transfusion services. BJOG. 2009; 116(5): 736-737.

PubMed Abstract | Publisher Full Text

4. Mumtaz Z, Bowen S, Mumtaz R: Meanings of blood, bleeding and blood donations in Pakistan: Implications for national vs global safe blood supply policies. Health Policy Plan. 2012; 27(2): 147-155. PubMed Abstract | Publisher Full Text | Free Full Text

5. Barro L, Drew VJ, Poda GG, et al.: Blood transfusion in sub-Saharan Africa: understanding the missing gap and responding to present and future challenges. Vox Sang. 2018; 113(8): 726-736. PubMed Abstract | Publisher Full Text

6. Valerian DM, Mauka WI, Kajeguka DC, et al.: Prevalence and causes of blood donor deferrals among clients presenting for blood donation in northern Tanzania. PLoS One. 2018; 13(10): e0206487. PubMed Abstract | Publisher Full Text | Free Full Text

7. Norton I, von Schreeb J, Aitken P, et al.: Classification and Minimum Standards for Foreign Medical Teams in Sudden Onset. World Heal Organ. 2013; 103. Reference Source

8. United Nations: MDG Gap Task Force Report 2015: Taking Stock of the Global Partnership for Development. 2015. Reference Source

9. Ghasemi E, Bashiri M: A Selective Covering-Inventory- Routing problem to the location of bloodmobile to supply stochastic demand of blood. International Journal of Industrial Engineering \& Production Research. 2018; 29(2): 147-158.

Publisher Full Text

10. MOH NBTS: Tanzania National Blood Transfusion Service Policy Guidelines. Dar es Salaam; 2005.

11. Mremi A, Yahaya IJ, Nyindo $M$, et al.: Transfusion-Transmitted Infections and associated risk factors at the Northern Zone Blood Transfusion Center in
Tanzania: A study of blood donors between 2017 and 2019. PLOS One. 2021; 16(3): e0249061.

PubMed Abstract | Publisher Full Text | Free Full Text

12. Jacobs B, Berege ZA: Attitudes and beliefs about blood donation among adults in Mwanza Region, Tanzania. East Afr Med J. 1995; 72(6): 345-348. PubMed Abstract

13. NBS\&OCGS: 2012 Population and Housing Survey, Population Distribution by Administrative areas. United Republic of Tanzania: National Bureau of Statistic, Ministry of Finance, and Zanzibar, Office of Chief Government Statistician, President's Office, Finance, Economy. 2013; 65.

14. Subedi D: Explanatory Sequential Mixed Method Design as the Third Research Community of Knowledge Claim. Am J Educ Res. 2016; 4(7): 570-577. Reference Source

15. Harvard Humanitarian Initiative: KoBoToolbox. Manual Kobo Toolbox. Reference Source

16. Finda F: Awareness, perceptions and practices of voluntary blood donations in Western and Northern Tanzania. Mendeley Data, V3, 2022. http://www.doi.org/10.17632/c6dkrj2bdd.3

17. Sarason IG, Sarason BR, Pierce GR, et al: A Social Learning Approach to Increasing Blood Donations. J App/ Soc Psychol. 1991; 21(11): 896-918. Publisher Full Text

18. Finch S, Thomason N, Cumming G: from the SAGE Social Science Collections. Downloaded. Theory Psychol. 2015; 12(6): 825-853.

19. Shidam UG, Lakshminarayanan S, Saurabh S, et al.: Knowledge and Attitude Regarding Blood Donation in Rural Puducherry, India. Natl J Community Med. 2015; 6(1): 64-68. Reference Source

20. Mathew SM, King MR, Glynn SA, et al.: Opinions about donating blood among those who never gave and those who stopped: A focus group assessment. Transfusion. 2007; 47(4): 729-735. PubMed Abstract | Publisher Full Text

21. Sen-Crowe B, McKenney K, McKenney M, et al.: Challenges associated with blood banks and blood donations during the COVID-19 pandemic. $A m \mathrm{~J}$ Emerg Med. 2021; 43: 281-282.

PubMed Abstract | Publisher Full Text | Free Full Text

22. Dhanakoses B: Management of Blood Donation: A Case Study of National Blood Centre of Thailand. 2016 


\section{Open Peer Review}

\section{Current Peer Review Status: $\mathrm{X}$}

\section{Version 1}

Reviewer Report 18 March 2022

https://doi.org/10.21956/aasopenres.14440.r29141

(C) 2022 Charles K. This is an open access peer review report distributed under the terms of the Creative Commons Attribution License, which permits unrestricted use, distribution, and reproduction in any medium, provided the original work is properly cited.

\section{Kenneth S. Charles}

Department of Paraclinical Sciences, Faculty of Medical Sciences, The University of the West Indies, St. Augustine, Trinidad and Tobago

This is a potentially valuable report on barriers to blood donation in a SubSaharan country. Much data from multiple sources using different methods is presented.

\section{General comments:}

The article substantiates data that has previously derived from several developing countries, most notably a mismatch between awareness and actual blood donation. This should be expanded in the discussion.

The authors need to describe the blood donation system in Tanzania. Although they claim exclusive voluntary blood donation, reference is made to donations "to help a family member" which constitutes family replacement donation. Country data for Tanzania must be given in the introduction to provide a background for demand vs supply. What eligibility criteria are used? The article alludes to a participant donating five times in twelve months. Why were the two study regions chosen? Their results should be compared using a column for $p$ values in Table 1 . The method used for random selection should be described to differentiate it from convenience sampling at various points in the studies. The differentiation between qualitative and quantitative methodology in the survey is unclear. It seems qualitative data was analyzed using quantitative methods. The questionnaire should be included.

The methodology applied cannot measure the magnitude of deficit stated in the abstract.

\section{References}

1. Charles KS: Blood transfusion in the Caribbean: a case study of Trinidad and Tobago.Transfus Med. 2017; 27 (1): 3-9 PubMed Abstract | Publisher Full Text

Is the work clearly and accurately presented and does it cite the current literature? 


\section{Partly}

Is the study design appropriate and is the work technically sound?

Partly

Are sufficient details of methods and analysis provided to allow replication by others? No

If applicable, is the statistical analysis and its interpretation appropriate?

No

Are all the source data underlying the results available to ensure full reproducibility? No

Are the conclusions drawn adequately supported by the results?

No

Competing Interests: No competing interests were disclosed.

Reviewer Expertise: Haematology and blood transfusion in developing countries

I confirm that I have read this submission and believe that I have an appropriate level of expertise to state that I do not consider it to be of an acceptable scientific standard, for reasons outlined above. 